\title{
Effects of ozone autohemotherapy on blood VEGF, TGF- $\beta$ and PDGF levels after finger replantation
}

\author{
Shaoyi He ${ }^{1}$, Weiting Chen ${ }^{2}$, Jingzhao Xia ${ }^{1}$, Zhongbin Lai ${ }^{1}$, Di Yu ${ }^{1}$, Ji Yao ${ }^{1}$, Shuiqi Cai ${ }^{3}$ \\ ${ }^{1}$ Department of Anesthesiology, The Third People's Hospital of Cixi City, Cixi, China; ${ }^{2}$ Department of Hand Surgery, The Third People's Hospital \\ of Cixi City, Cixi, China; ${ }^{3}$ Department of Orthopedics, The Third People's Hospital of Cixi City, Cixi, China \\ Contributions: (I) Conception and design: S He, S Cai; (II) Administrative support: J Yao; (III) Provision of study materials or patients: D Yu, W \\ Chen; (IV) Collection and assembly of data: J Xia; (V) Data analysis and interpretation: S Cai, Z Lai; (VI) Manuscript writing: All authors; (VII) Final \\ approval of manuscript: All authors. \\ Correspondence to: Shuiqi Cai. Department of Orthopedics, The Third People's Hospital of Cixi City, No.40, Zhengong Road, Zhouxiang Town, Cixi \\ 315324, China. Email: caishuiqi123@hotmail.com.
}

Background: The study aimed to confirm the important role of ozone autologous blood therapy (autohemotherapy) in promoting successful finger replantation and its possible influence mechanism.

Methods: A total of 150 patients with severed finger replantation admitted to our hospital from March 2018 to March 2019 were selected. Patients were divided into observation group and control group according to different treatment methods. The observation group received additional ozone autologous blood treatment in the control group. We compared the number of white blood cells, visual analogue scale (VAS) scores, and the expression levels of vascular endothelial growth factor (VEGF), transforming growth factor- $\beta$ (TGF- $\beta$ ), and platelet-derived growth factor (PDGF) in the two groups of patients before and after intervention. We also assessed the hospitalization time and survival time of the replanted finger in the two groups, as well as blood flow values (Vbcf).

Results: Compared with the observation group on the 1st day after the operation and the control group on the 7th day after the operation, the average white blood cell count of the observation group on the 7 th day after the operation was significantly increased $(\mathrm{P}<0.05)$, and the VAS score was significantly decreased $(\mathrm{P}<0.05) .48$ hours after the operation, the average Vbcf value of the replanted finger was lower than that of the contralateral healthy finger $(\mathrm{P}<0.05)$. Compared with the control group, the Vbcf value of the replanted fingers in the observation group was higher, and the hospitalization time and finger survival time were shorter $(\mathrm{P}<0.05)$. At 7 days after operation, the serum VEGF, TGF- $\beta$ and PDGF levels in the observation group were significantly higher than the 1 day after operation, before the operation and the control group $(\mathrm{P}<0.05)$.

Conclusions: Intervention with ozone autohemotherapy after severed finger replantation can significantly increase the number of white blood cells, relieve postoperative pain, and improve the survival rate of the finger body. Ozone autohemotherapy also improves the microcirculation after anastomosis of the severed finger by up-regulating the expression of VEGF, TGF- $\beta$ and PDGF in blood.

Keywords: Ozone autohemotherapy; finger replantation; vascular endothelial growth factor; transforming growth factor- $\beta$ (TGF- $\beta$ ); platelet-derived growth factor (PDGF)

Submitted Jul 01, 2020. Accepted for publication Sep 11, 2020.

doi: 10.21037/apm-20-1467

View this article at: http://dx.doi.org/10.21037/apm-20-1467 


\section{Introduction}

With the continuous development of industrialization, finger accidents due to production have increased year by year. Replantation is the surgical technique used to repair a severed finger. The replantation of a severed finger involves re-anatomizing the blood vessels, nerves and tendons of the finger using microsurgical techniques to restore the patient's finger structure and function and reduce the occurrence of disability (1). Finger replantation is a process of organizational rebuilding and functional rebuilding, generally in two stages. First, the replanted finger survives, and second, finger function recovers. Although there are effective technologies and a high success rate of finger replantation, the low survival rate of the severed finger during the survival stage due to various reasons is the main reason for failure of finger replantation. The recovery process after finger replantation is often complicated by severe pain, infection, and blood flow issues, and these risks influence the recovery of the replanted finger. Therefore, improving the finger survival rate after replantation is the key to postoperative rehabilitation (2). Routine postoperative care includes analgesic treatment, as well as anti-biotics, anticoagulation, anti-spasm and other blood flow recovery treatment approaches. Despite this, replantation still has a low success rate due to pain, infection and impaired blood flow recovery. The failure of severed finger survival can result in long-term disability in patients (3).

In recent years, studies have found that ozone is effective for improving the blood oxygen saturation of local tissue cells and improving the microcirculation function of damaged tissues (4). Based on these clinical findings, ozone autologous blood therapy (autohemotherapy) has been widely used in the prognosis of stroke patients and achieved satisfactory results. However, there are few reports regarding the improvement of local microcirculatory function after finger replantation (5). This study aims to assess the impact of early intervention ozone autohemotherapy after severed finger replantation. We present the following article in accordance with the CONSORT reporting checklist (available at http://dx.doi. org/10.21037/apm-20-1467).

\section{Methods}

\section{Study population}

A total of 150 patients with a severed finger admitted to our hospital between March 2018 and March 2019 were selected. This included 97 males and 53 females aged $18-60$ years, with an average age of $33.27 \pm 4.66$ years. The inclusion criteria were as follows: indications for replantation surgery (completely dissected, neat, intact finger body, no serious contusion); injury to operation time $<12$ hours; no systemic diseases or other factors affecting finger healing. Replantation surgery patients provided informed consent and accepted the conditions of this project, and replantation surgery was performed by the same group of surgeons. The exclusion criteria were as follows: glucose-6-phosphate dehydrogenase deficiency, toxic hyperthyroidism-Basedow Graves syndrome, thrombocytopenia below 50,000 and severe coagulopathy, acute myocardial infarction, massive and acute bleeding, epilepsy patients, hemochromatosis disease, patients receiving copper or iron treatment, psychosis, drug dependence, trioxygen allergy and citric acid allergy. The project's research and treatment plan was submitted to the Ethics Committee of Cixi Third People's Hospital for approval and implementation (No. 2019-LP-03). All procedures performed in this study involving human participants were in accordance with the Declaration of Helsinki (as revised in 2013). According to different treatment methods, patients were divided into an observation group or a control group, with 75 patients in each group. The difference in baseline data between the two groups was not statistically significant $(\mathrm{P}>0.05$, Table 1$)$, indicating they were comparable.

\section{Treatment method}

For the control group, treatment was as follows: Intravenous infusion of antibiotics for 3 days; intramuscular injection of papaverine $30 \mathrm{mg} 3$ times a day; intramuscular injection of anisodamine $5 \mathrm{mg}$ once a day; intravenous infusion of low molecular dextran $500 \mathrm{~mL}$ once a day for 7 consecutive days; replanted fingers are irradiated with electromagnetic wave physiotherapy to keep warm and the patient was kept in bed for 7 days. For the observation group, treatment was the same as the treatment of the control group, with the addition of simultaneous ozone autohemotherapy. A medical ozone generator (Carter, Germany) was used. Venous blood was collected from the patient's upper limb $(100 \mathrm{~mL})$ in a closed sterile system, and $2.5 \%$ citric acid was added to sodium anticoagulant $(20 \mathrm{~mL})$. After being thoroughly mixed with $100 \mathrm{~mL}$ of ozone with a concentration of $30 \mu \mathrm{g} / \mathrm{mL}$, this was intravenously infused within 20 minutes and the patient was 
Table 1 Comparison of two general data $(\bar{x} \pm s)$ [n (\%)]

\begin{tabular}{|c|c|c|c|c|}
\hline & Observation group $(n=75)$ & Control group $(n=75)$ & $t$ & $\mathrm{P}$ \\
\hline Sex $(\%)$ & & & 0.263 & 0.608 \\
\hline Male & $51.55(50 / 97)$ & $48.45(47 / 97)$ & & \\
\hline Female & $47.17(25 / 53)$ & $52.83(28 / 53)$ & & \\
\hline Sharp cut & $60.71(17 / 28)$ & $39.29(11 / 28)$ & & \\
\hline Blunt cut & $48.61(35 / 72)$ & $51.39(37 / 72)$ & & \\
\hline Crush injury & $46.00(23 / 50)$ & $54.00(27 / 50)$ & & \\
\hline Separated plane & & & 1.534 & 0.464 \\
\hline Distal phalanx & $48.28(28 / 58)$ & $51.72(30 / 58)$ & & \\
\hline
\end{tabular}

treated once every 24 hours for 7 consecutive days.

\section{Observation indicators}

Patients underwent a blood test to determine white blood cell counts. For pain assessment, the visual analogue scale (VAS) was used, where 0 points indicated no pain; 1-3 points indicated mild pain, but still able to engage in normal activities; 4-6 points indicated moderate pain, which affects work, but the patient could still take care of themselves; 7-9 points indicated more severe pain, resulting in the patient falling asleep and could not take care of themselves; 10 points indicated severe or unbearable pain.

To detect replanted finger blood flow, a laser Doppler image diagnosis system was used, generating finger blood flow values $\left(\mathrm{V}_{\mathrm{bcf}}\right)$. If the replanted finger has a good blood flow recovery condition, the finger body is ruddy, the finger temperature detection is close to or lower than $1-2{ }^{\circ} \mathrm{C}$, the fingertip tension is the same as or slightly higher than the healthy side finger, and the capillary filling test is good, and If no infection is found in the severed finger, the replanted severed finger can be considered alive and the time recorded (6).

To detect the expression levels of vascular endothelial growth factor (VEGF), transforming growth factor- $\beta$ (TGF- $\beta$ ) and platelet-derived growth factor (PDGF) in blood, before and after treatment and after the intervention,
$5 \mathrm{ml}$ of blood was drawn from the upper limb veins of each patient into an EDTA-Na anticoagulation tube. This was followed by centrifugation at $1,000 \mathrm{~g}$ for 10 minutes. The supernatant was collected and divided into $200 \mu \mathrm{L} /$ tube, labelled, and stored at $-80^{\circ} \mathrm{C}$.

\section{ELISA}

A double sandwich method ELISA assay was used to detect the expression levels of VEGF, TGF- $\beta$ and PDGF. (I) Thaw and thaw samples, restore the reagent to room temperature, and determine the number of samples. (II) Set up blank wells, standard wells, and sample wells. Accurately add $50 \mu \mathrm{L}$ of the standard on the enzyme-coated plate. Add $40 \mu \mathrm{L}$ of sample diluent to the well of the sample to be tested, and then add $10 \mu \mathrm{L}$ of the sample to be tested. (III) Incubation: seal the plate with a sealing film and incubate at $37^{\circ} \mathrm{C}$ for 30 minutes. (IV) Mixing solution. (V) Add enzyme. (VI) Incubation. (VII) Washing. (VIII) Color development. (IX) Termination. (X) Determination.

\section{Follow-up method}

At 1 and 7 days after surgery, white blood cell counts, VAS scores, and $\mathrm{V}_{\mathrm{bcf}}$ values of the two groups were recorded at 48 hours after surgery. Hospitalization time and finger survival time of the two groups were observed. Finally, the serum levels of VEGF, TGF- $\beta$ and PDGF were recorded 
Table 2 Comparison of the number of white blood cells at different times after replantation surgery between the two groups $\left(\bar{x} \pm s, \times 10^{9}\right)$

\begin{tabular}{lccc}
\hline Group & $\mathrm{n}$ & 1 day post-surgery & 7 days post-surgery \\
\hline Observation group & 75 & $7.31 \pm 1.59$ & $8.54 \pm 2.16^{*}$ \\
Control group & 75 & $7.24 \pm 1.78$ & $7.32 \pm 1.93$ \\
$t$ & - & 0.076 & 3.146 \\
$\mathrm{P}$ & - & $>0.05$ & $<0.05$ \\
\hline
\end{tabular}

Compared with 1 day after operation, ${ }^{*} \mathrm{P}<0.05$.

Table 3 Comparison of visual analogue scale (VAS) scores between the two groups of patients at different times after replantation surgery $(\bar{x} \pm s$, points)

\begin{tabular}{lccc}
\hline Group & $\mathrm{n}$ & 1 day post-surgery & 7 days post-surgery \\
\hline Observation group & 75 & $6.24 \pm 1.66$ & $1.22 \pm 0.21^{*}$ \\
Control group & 75 & $6.40 \pm 1.71$ & $3.14 \pm 0.65$ \\
$t$ & - & 0.041 & 3.776 \\
$\mathrm{P}$ & - & $>0.05$ & $<0.05$ \\
\hline
\end{tabular}

Compared with 1 day after operation, ${ }^{*} \mathrm{P}<0.05$.

before the operation, 1 day and 7 days after the surgery. Recorded to 7 days after the operation, the study data collection is over after the treatment is completed.

\section{Statistical analysis}

SPSS 21.0 statistical software was used for analysis. Data was expressed as mean \pm standard deviation $(\bar{x} \pm s)$. Using $t$ tests and repeated measures analysis of variance to test. Bonferroni is used for post-mortem inspection. $\mathrm{P}<0.05$ indicated that the difference was statistically significant.

\section{Results}

\section{Higher white blood cell counts post-surgery after ozone autohemotherapy}

There was no significant difference in white blood cell count between the two groups 1 day after replantation surgery $(\mathrm{P}>0.05)$. At 7 days post-operation, the white blood cell count in the observation group was higher than that in the 1 day post-operative and control groups, and the difference was statistically significant $(\mathrm{P}<0.05$, Table 2).

\section{Postoperative pain scores after finger replantation are lowered by ozone autohemotherapy}

There was no significant difference between the VAS scores of the two groups 1 day after surgery $(\mathrm{P}>0.05)$. The VAS scores of the two groups at 7 days post-surgery were lower than those at 1 day post-surgery. The VAS scores in the observation group were lower than those in the control group at 7 days post-surgery, and this was statistically significant $(\mathrm{P}<0.05$, Table 3).

\section{Blood flow after finger replantation is greater after ozone autohemotherapy}

The $V_{\text {bcf }}$ values of the replanted fingers across the two groups were lower than that of the contralateral healthy fingers 48 hours after surgery. The $V_{b c f}$ values of the replanted fingers in the observation group were higher than the control group, and the difference was statistically significant $(\mathrm{P}<0.05$, Table 4).

\section{Hospitalization time and finger survival time is shorter after ozone autohemotherapy}

The average hospitalization and finger survival times in the 
Table 4 Comparison of blood flow values (Vbcf) between replanted fingers and contralateral healthy fingers in the two treatment groups $(\bar{x} \pm s)$

\begin{tabular}{lccc}
\hline Group & $\mathrm{n}$ & Contralateral healthy finger & Replanted fingers \\
\hline Observation group & 75 & $26.50 \pm 4.78$ & $21.68 \pm 3.20^{*}$ \\
Control group & 75 & $26.22 \pm 4.56$ & $15.23 \pm 2.87^{*}$ \\
$t$ & - & 0.051 & 6.821 \\
$\mathrm{P}$ & - & $>0.05$ & $<0.05$ \\
\hline
\end{tabular}

Compared with the healthy fingers, ${ }^{*} \mathrm{P}<0.05$.

Table 5 Comparison of hospitalization time and finger survival time between the two treatment groups $(\bar{x} \pm s)$

\begin{tabular}{lccc}
\hline Group & $\mathrm{n}$ & Hospitalization time $(\mathrm{d})$ & Finger survival time $(\mathrm{d})$ \\
\hline Observation group & 75 & $14.21 \pm 3.04$ & $6.43 \pm 1.46$ \\
Control group & 75 & $18.77 \pm 4.52$ & $9.60 \pm 2.28$ \\
$t$ & - & 5.112 & 9.056 \\
$\mathrm{P}$ & - & $>0.05$ & $<0.05$ \\
\hline
\end{tabular}

observation group were shorter than the control group, and the difference was statistically significant $(\mathrm{P}<0.05$, Table 5).

\section{VEGF, TGF- $\beta$ and PDGF expression levels decrease with ozone autohemotherapy after finger replantation}

There was no significant difference in serum VEGF, TGF- $\beta$ and PDGF levels between the two treatment groups 1 day after surgery and before operation $(\mathrm{P}>0.05)$. The serum VEGF, TGF- $\beta$ and PDGF levels in the observation group were lower 1 day after surgery and before operation compared to an increase at 7 days post-surgery. The expression levels remained higher than the control group at 7 days post-surgery, and this difference was statistically significant $(\mathrm{P}<0.05$, Table 6).

\section{Discussion}

Since the 1920s, ozone therapy has been widely used in clinics all over the world. Due to its therapeutic effects and broad therapeutic indications, it has long been a focus in medical research. According to the different methods of introducing ozone into the body, ozone treatments can be divided into large autologous blood transfusion methods, small autologous blood transfusion methods, rectal gas perfusion, whole body exposure, ozone gas bath therapy and ozone water treatment methods. The clinical application of ozone is the ozone autologous blood transfusion method, also known as ozone autohemotherapy. This method uses an ozone generator to mix autologous blood and ozone in a sterile environment, and return it to the body for disease treatment (7). The significant therapeutic effects of ozone therapy have been demonstrated in clinics all over the world, providing hope for the treatment of a large number of diseases.

Our study showed that the average white blood cell count of patients in the observation group was higher 7 days after surgery compared to 1 day after surgery, and was also higher than that of the control group. Similarly, the VAS scores of the two groups 7 days after surgery was lower than that at 1 day after surgery, and the VAS score of the observation group was lower than that of the control group. This suggests that ozone intervention has a good analgesic effect. It is also suggested that ozone can stimulate the proliferation of leukocytes, and induce certain antiinflammatory effects. At 48 hours post-surgery, the $V_{\text {bcf }}$ values of the replanted fingers in the observation group was higher than the control group. This suggests that the average blood flow of the skin at the end of the replanted finger after ozone intervention is significantly increased, which can reduce the occurrence of vascular crisis. The hospitalization times and finger survival times in the observation group were shorter than the control group, suggesting that ozone intervention can increase the survival of replanted fingers.

At present, there are some controversies surrounding the 
Table 6 Comparison of blood VEGF, TGF- $\beta$ and PDGF levels between the two treatment groups at different time points after finger replantation $(\bar{x} \pm s)$

\begin{tabular}{|c|c|c|c|c|}
\hline & Observation group $(n=75)$ & Control group $(n=75)$ & $\mathrm{t}$ & $P$ \\
\hline Before operation & $4.65 \pm 0.68$ & $4.83 \pm 0.75$ & 1.540 & 0.126 \\
\hline $1 \mathrm{~d}$ after operation & $5.81 \pm 1.11^{*}$ & $5.92 \pm 1.14^{*}$ & 0.599 & 0.550 \\
\hline $7 \mathrm{~d}$ after operation & $27.78 \pm 3.77^{\star *}$ & $7.14 \pm 2.05^{\star *}$ & 41.653 & $<0.001$ \\
\hline$P$ & $<0.001$ & & - & - \\
\hline $\mathrm{F}_{\text {Time }}$ & $2,031.049$ & & - & - \\
\hline$P$ & $<0.001$ & & - & - \\
\hline$F_{\text {groups }}$ & $1,413.580$ & & - & - \\
\hline Before operation & $4.05 \pm 0.85$ & $3.94 \pm 0.91$ & 0.765 & 0.446 \\
\hline $1 \mathrm{~d}$ after operation & $4.67 \pm 1.08^{*}$ & $4.71 \pm 1.12^{*}$ & 0.223 & 0.824 \\
\hline $7 \mathrm{~d}$ after operation & $8.49 \pm 1.37^{\star *}$ & $5.57 \pm 1.20^{\star *}$ & 13.885 & $<0.001$ \\
\hline $\mathrm{F}_{\text {Interaction }}$ & 85.824 & & - & - \\
\hline$P$ & $<0.001$ & & - & - \\
\hline $\mathrm{F}_{\text {Time }}$ & 312.21 & & - & - \\
\hline $\mathrm{P}$ & $<0.001$ & & - & - \\
\hline$F_{\text {groups }}$ & 91.998 & & - & - \\
\hline$F_{\text {Interaction }}$ & 456.918 & & - & - \\
\hline$P$ & $<0.001$ & & - & - \\
\hline $\mathrm{F}_{\text {Time }}$ & 845.390 & & - & - \\
\hline $\mathrm{P}$ & $<0.001$ & & - & - \\
\hline$F_{\text {groups }}$ & 480.191 & & - & - \\
\hline$P$ & $<0.001$ & & - & - \\
\hline
\end{tabular}

Compared with before operation, ${ }^{*} \mathrm{P}<0.05$, compared with 1 day after operation; ${ }^{*} \mathrm{P}<0.05$.

mechanisms underlying ozone therapy. Some researchers (8) believe that ozone predominantly activates the extracellular regulatory protein kinase $\mathrm{P} 38$, which in turn activates the Nrf2/EpRE pathway, and ultimately promotes superoxide dismutase and catalase to exert an antioxidant effect. Other researchers have suggested that ozone therapy stimulates the body's non-specific immune response, promoting white blood cell phagocytosis, thus regulating the body's immune 
environment and enhancing immunity (9). In addition, previous studies have suggested that ozone can activate red blood cell metabolism, improve the oxygen saturation of hemoglobin, and enhance the use of oxygen and ATP by tissues (10). Although the underlying mechanisms of ozone treatment are not yet clear, it is nonetheless effective across a broad spectrum of diseases. A large number of studies have found that ozone has a significant therapeutic effect on wound healing of diabetic feet, atherosclerosis, lumbar intervertebral disc herniation, chronic hepatitis and other diseases $(11,12)$.

It has been previously shown that ozone plays a role in three aspects of treatment, namely analgesia, antiinfection and vascular repair, of which vascular repair is the most important role (13). Rivas et al. (14) confirmed using immunohistochemistry that injection of ozone into the joint cavity increased the expression of HIF- $1 \alpha$ in synovial tissue, initiating the transcription and expression of VEGF, thereby promoting vascular proliferation and the formation of pannus. Villwock et al. and other(15) groups have confirmed that TGF- $\beta 1$ has a chemotactic effect on endothelial cells, which induces angiogenesis and promotes wound healing. PDGF has a chemotactic effect on neutrophils, monocytes, and fibroblasts, allowing these cells to migrate to wounded tissues. PDGF is also a mitogen for fibroblasts, inducing the regeneration of fibroblasts and increasing the granulation tissue. PDGF can also activate macrophages in the body to synthesize VDGF, which further promotes angiogenesis. The chemotaxis, activation and induction of PDGF in different cells are beneficial to tissue repair at the wound site and accelerating wound healing. Wang et al. treated diabetic foot using ozone therapy and found that the expression levels of VEGF, TGF- $\beta$ and PDGF in wound secretions significantly increased. Consistent with this, our study showed that serum VEGF, TGF- $\beta$, and PDGF levels in the observation group were higher than those in the control group 7 days post-surgery. Therefore, ozone can achieve blood vessel repair by up-regulating the expression of VEGF, TGF- $\beta$ and PDGF in the blood.

Due to the limitations of the experimental conditions in this study, the patients were not randomized. Therefore, the experimental results may still have certain deviations. Secondly, our current study failed to focus on the specific mechanisms of ozone therapy affecting VEGF, TGF- $\beta$ and PDGF. This will become the direction of our followup research. We also expect other scholars to provide new insights from different perspectives.

In summary, ozone autologous blood therapy after replantation can significantly increase finger survival and recovery. Ozone autohemotherapy also increased the number of white blood cells, relieved postoperative pain, and improved the microcirculation at the anastomosis site.

\section{Acknowledgments}

Funding: None.

\section{Footnote}

Reporting Checklist: The authors have completed the CONSORT reporting checklist. Available at http://dx.doi. org/10.21037/apm-20-1467

Data Sharing Statement: Available at http://dx.doi. org/10.21037/apm-20-1467

Conflicts of Interest: All authors have completed the ICMJE uniform disclosure form (available at http://dx.doi. org/10.21037/apm-20-1467). The authors have no conflicts of interest to declare.

Ethical Statement: The authors are accountable for all aspects of the work in ensuring that questions related to the accuracy or integrity of any part of the work are appropriately investigated and resolved. The project's research and treatment plan was submitted to the Ethics Committee of Cixi Third People's Hospital for approval and implementation (No. 2019-LP-03). Replantation surgery patients provided informed consent and accepted the conditions of this project. All procedures performed in this study involving human participants were in accordance with the Declaration of Helsinki (as revised in 2013).

Open Access Statement: This is an Open Access article distributed in accordance with the Creative Commons Attribution-NonCommercial-NoDerivs 4.0 International License (CC BY-NC-ND 4.0), which permits the noncommercial replication and distribution of the article with the strict proviso that no changes or edits are made and the original work is properly cited (including links to both the formal publication through the relevant DOI and the license). See: https://creativecommons.org/licenses/by-nc-nd/4.0/.

\section{References}

1. Dall'Olio M, Princiotta C, Cirillo L, et al. Oxygen-ozone 
therapy for herniated lumbar disc in patients with subacute partial motor weakness due to nerve root compression. Interv Neuroradiol 2014;20:547-54.

2. Domb WC. Ozone therapy in dentistry. A brief review for physicians. Interv Neuroradiol 2014;20:632-6.

3. Wu X, Li Z, Liu X, et al. Major ozonated autohemotherapy promotes the recovery of upper limb motor function in patients with acute cerebral infarction. Neural Regen Res 2013;8:461-8.

4. Wang WJ, Zhan Y, Zhang DY, et al. Research progress in treatment and nursing of vascular crisis after replantation of severed finger. Journal of Traumatic Surgery 2016;18:572-4.

5. Rangel-Castilla L, Hopkins LN. Safety and Efficacy of Stent Retrievers for the Management of Acute Ischemic Stroke. JACC Cardiovasc Interv 2015;8:1766-7.

6. Wang Y, Yu J, Zhang D, et al. Addition of hydrogen peroxide for the simultaneous control of bromate and odor during advanced drinking water treatment using ozone. J Environ Sci (China) 2014;26:550-4.

7. Xing B, Chen H, Wang L, et al. Ozone oxidative preconditioning protects the rat kidney from reperfusion injury via modulation of the TLR4-NF- $\kappa \mathrm{B}$ pathway. Acta Cir Bras 2015;30:60-6.

8. Sancak EB, Turkön H, Çukur S, et al. Major Ozonated Autohemotherapy Preconditioning Ameliorates Kidney Ischemia-Reperfusion Injury. Inflammation 2016;39:209-17.

Cite this article as: He S, Chen W, Xia J, Lai Z, Yu D, Yao J, Cai S. Effects of ozone autohemotherapy on blood VEGF, TGF- $\beta$ and PDGF levels after finger replantation. Ann Palliat Med 2020;9(5):3332-3339. doi: 10.21037/apm-20-1467
9. Onder H, Murat Arsava E, Arat A, et al. Acute Middle Cerebral Artery Occlusion Treated by Thrombectomy in a Patient with Myelodysplastic Syndrome and Severe Thrombocytopenia. J Vasc Interv Neurol 2015;8:22-6.

10. Gultekin FA, Cakmak GK, Turkcu UO, et al. Effects of ozone oxidative preconditioning on liver regeneration after partial hepatectomy in rats. J Invest Surg 2013;26:242-52.

11. Ozkan H, Ekinci S, Uysal B, et al. Evaluation and comparison of the effect of hypothermia and ozone on ischemia-reperfusion injury of skeletal muscle in rats. J Surg Res 2015;196:313-9.

12. Chantepie SP, Mear JB, Guittet L, et al. Transfusion strategy in hematological intensive care unit: study protocol for a randomized controlled trial. Trials 2015;16:533.

13. Aydos TR, Başar MM, Kul O, et al. Effects of ozone therapy and taurine on ischemia/reperfusion-induced testicular injury in a rat testicular torsion model. Turk J Med Sci 2014;44:749-55.

14. Rivas M, Ratra A, Nugent K. Obstructive sleep apnea and its effects on cardiovascular diseases: a narrative review. Anatol J Cardiol 2015;15:944-50.

15. Villwock MR, Padalino DJ, Deshaies EM. Carotid Artery Stenosis with Acute Ischemic Stroke: Stenting versus Angioplasty. J Vasc Interv Neurol 2015;8:11-6.

(English Language Editor: C. Betlazar-Maseh) 